\title{
Harmonics and Coupling-terms in the Pulsation of the Double-mode Cepheid TU Cas
}

\author{
L. Szabados \\ Konkoly Observatory, Hungary
}

\begin{abstract}
Preliminary results of the period analysis of the double-mode Cepheid TU Cassiopeiae are given. Up to now 29 frequencies have been identified: the frequency of the fundamental mode pulsation and the first overtone, and their linear combinations. The amplitudes of the frequency constituents show temporal variations.
\end{abstract}

First results of the analysis based on the largest homogeneous photometric data set on the double-mode Cepheid TU Cas are given. The UBV observations (more than 400 data points in each color) obtained during 14 years, especially the rich sample (160 observations on 86 nights) in a single observational season (1973/74) allowed the determination of a large number of frequencies present in the Fourier-spectrum of this bright beat Cepheid.

The following frequencies have been identified:

$\mathrm{f}_{0}, 2 \mathrm{f}_{0}, 3 \mathrm{f}_{0}, 4 \mathrm{f}_{0}, 5 \mathrm{f}_{0}, 6 \mathrm{f}_{0}$,

$\mathrm{f}_{1}, 2 \mathrm{f}_{1}, 3 \mathrm{f}_{1}$,

$\mathrm{f}_{0}+\mathrm{f}_{1}, 2 \mathrm{f}_{0}+2 \mathrm{f}_{1}, 3 \mathrm{f}_{0}+3 \mathrm{f}_{1}$,

$2 \mathrm{f}_{0}+\mathrm{f}_{1}, 3 \mathrm{f}_{0}+\mathrm{f}_{1}, 4 \mathrm{f}_{0}+\mathrm{f}_{1}, 5 \mathrm{f}_{0}+\mathrm{f}_{1}, 6 \mathrm{f}_{0}+\mathrm{f}_{1}$,

$\mathrm{f}_{0}+2 \mathrm{f}_{1}, 3 \mathrm{f}_{0}+2 \mathrm{f}_{1}, 4 \mathrm{f}_{0}+2 \mathrm{f}_{1}, 5 \mathrm{f}_{0}+2 \mathrm{f}_{1}$,

$\mathrm{f}_{0}+3 \mathrm{f}_{1}, 2 \mathrm{f}_{0}+3 \mathrm{f}_{1}, 4 \mathrm{f}_{0}+3 \mathrm{f}_{1}$,

$\mathrm{f}_{1}-\mathrm{f}_{0}, 2 \mathrm{f}_{1}-\mathrm{f}_{0}, 3 \mathrm{f}_{1}-\mathrm{f}_{0}$,

$2 \mathrm{f}_{0}-\mathrm{f}_{1}, 3 \mathrm{f}_{0}-\mathrm{f}_{1}$,

where $\mathrm{f}_{0}=0.46734 \mathrm{c} / \mathrm{d}$ is the frequency of the fundamental mode oscillation, while $\mathrm{f}_{1}=0.65860 \mathrm{c} / \mathrm{d}$ is that of the first overtone.

The preliminary analysis of the whole data set already revealed the temporal variation of the amplitudes. These changes can be studied when comparing with the results of Matthews et al. (personal communication).

The period analysis was performed with the help of the MUFRAN-package developed by $\mathrm{Z}$. Kolláth. Thanks are due to him for putting this software at the author's disposal. The travel support from OTKA (Hungary) and IAU is gratefully ackowledged. 